ORIGINAL ARTICLE

\title{
Reproductive Health Practice of Married Women in the Rural
} Community of Dhamrai Upazila, Dhaka

\author{
*M Rahman ${ }^{1}$, A Rahman $^{2}$, TT Sajoni ${ }^{3}$, SA Chowdhury ${ }^{4}$, A Akhter ${ }^{5}$ \\ ${ }_{1}^{1}$ Prof. Dr. Md. Mahfuzar Rahman, Professor and Head, Dept. of Community Medicine, AKMMC \\ ${ }^{2}$ Dr. Md. Atiqur Rahman, Assistant professor, Dept. of Community Medicine, AKMMC \\ ${ }^{3}$ Dr. Tabassum Tahmin Sajani, Assistant professor, Dept. of Community Medicine, AKMMC \\ ${ }^{4}$ Dr. Samia Ahmed Chowdhury, Lecturer, Dept. of Community Medicine, AKMMC \\ ${ }^{5}$ Dr. Arifa Akhter, Lecturer, Dept. of Community Medicine, AKMMC
}

*Corresponding author

\begin{abstract}
Reproductive health is an emerging issue in Bangladesh as well as in the world. Women reproductive health is relatively a new area of health intervention in Bangladesh and recently it is an important issue. Among the women, married adolescents are particularly vulnerable regarding reproductive health problem in Bangladesh. This descriptive cross sectional study was carried among 534 married women of reproductive age by purposive sampling from 22nd to 28th December, 2012 in different villages of Dhamrai Upazila, Dhaka. Data were collected on a pretested questionnaire by face to face interview. Data were analyzed manually and by using computer. The study revealed that majority of the women had either primary (33\%) or secondary level (39\%) education with mean age of $29 \pm 7.33$ years. Most of them (86\%) were house-wives and dependant on their husband for financial support and major segment (52\%) had poor monthly income (TK <9000). Among all, about $58 \%$ respondents were found having 2-4 number of children and $58 \%$ gave birth of first child during adolescence (15-19 years) with mean age of $19 \pm 3.5$ years. About $(79 \%)$ received TT immunization and $(77 \%)$ utilized antenatal care. Most of the delivery $(52 \%)$ were conducted at home by skilled birth attendant $(30 \%)$ and untrained birth attendant $(22 \%)$. About $31 \%$ had problems during last pregnancy. Among them adverse outcomes were Abortion (21\%), PPH (22\%) and Obstructed labor (28\%). Reproductive health problems faced by the women included Menstrual disturbance (52\%), Leucorrhoea (41\%) and Urinary Tract Infections (35\%). Reproductive health practice was still worse among the rural community of the study area. The study recommends formulation and implementation of effective strategies to improve reproductive health status of the rural women.
\end{abstract}

Key words: Health seeking behavior, Surviellance, Morbidity pattern

\section{Introduction}

Reproductive health implies that people are able to have a responsible, satisfying and safe sexual life and that they have the capability to reproduce and the freedom to decide if, when and how often to do so ${ }^{1}$. In the past few years, the issues of reproductive health have been increasingly perceived as social problem; they have emerged as a matter of increasing concern throughout the developed and developing countries. Women reproductive health is relatively a new area of health intervention in
Bangladesh and recently it is an important issue. Among the women, married adolescents are particularly vulnerable regarding reproductive health problem in Bangladesh ${ }^{2}$. The program of Action of the International Conference on Population and Development (ICPD), held in Cairo in 1994, defined reproductive health in a comprehensive manner to encompass physical, mental, and social wellbeing in all matters relating to the reproductive system and to its function in consists and process. Thus in 
contrast with previous approaches that focused on specific aspects of reproductive health, such as safe motherhood, maternal and child health and family planning. The reproductive health approach is concerned not only with pregnancy related health issue, but also with health and human right issues relevant to reproductive and sexuality that arise with health and human rights issues relevant to reproductive and sexuality that arise within and outside the child bearing age ${ }^{3}$.

Many countries have become increasingly involved in monitoring reproductive rights and use the reporting procedures for international human rights instruments that their governments have ratified. In Bangladesh, the barriers towards establishment of women's sexual and reproductive health rights are in everlasting difficulty due to malnutrition, illiteracy, and higher gender inequality ${ }^{4}$. Study on reproductive health rights reveals a wide range of socioeconomic and demographic factors which affect women's empowerment, education and reproductive health rights. The socioeconomic and demographic characteristics of people in a particular society are likely to be different from each other. These may also vary from one geographical setting to another ${ }^{5}$.

In developing world, $1 / 3 \mathrm{rd}$ of all healthy adult women are lost due to reproductive health problem $^{6}$. Female population is about 60.26 million in Bangladesh and married women of reproductive age group constitute $51.7 \%$ of total female population ${ }^{7,8}$. More than 500,000 women die every year due to pregnancy related complications in the developing world ${ }^{9}$. In although the average age at first marriage is 18 years for females and 27 years for males, rural females tend to marry even earlier. Approximately $75 \%$ of the girls are married before the age of 16 , and only $5 \%$ are married after 18 years, which is the legal ageof marriage for females in Bangladesh ${ }^{6}$. Like early marriage, early pregnancy is common among females in Bangladesh. The adolescent fertility rate in the country is one of the highest in the world with 147 births per 1,000 women aged $<20$ years ${ }^{10}$. Utilization of reproductive healthcare services such as antenatal care (ANC), institutional delivery attended by trained birth attendants are basic needs for pregnant mothers around the globe. In our country, antenatal care coverage (at least one visit) is $48.7 \% 8$ and most of the deliveries $(87.4 \%)$ takes place at home, only $11.2 \%$ deliveries occur in hospitals or clinics ${ }^{11}$. The number of births attended by skilled health personnel is $13 \% 12$. In Bangladesh different factors in many forms and folds affect the reproductive health of married women specially in rural communities.

The Government of Bangladesh seeks to create conditions whereby the people of Bangladesh have the opportunity to reach and maintain the highest attainable level of health. MOHFW adopted in 1998 the Health and Population Sector Strategy (HPSS) to provide a package of essential health care services for the people of Bangladesh and to slow down population growth ${ }^{13}$. The main sectorial objectives of the HPSS are: maintenance of the momentum of efforts in Bangladesh to lower fertility and reduce mortality, reduction of maternal mortality and morbidity and reduction in the burden of communicable diseases. Barkat14 suggested that the essential services package identified in the HPSS consists of basic reproductive and child health services, including family planning, maternal care and immunization as well as control of selected communicable diseases, limited curative care and behavior change communication. The Health and Population Sector Program (HPSP) was formulated in 1998 on the basis of HPSS. In order to encompass all the activities of the health sector, the Government has revised the HPSP and formulated the new 'Health, Nutrition and Population Sector Program (HNPSP), 2003-2006 ${ }^{15}$. The vision and targets outlined in the Interim Poverty Reduction Strategy Paper (i-PRSP) of the government have been adopted as overarching long-term policy framework for HNPSP. As noted by ${ }^{16}$ the reproductive health approach reflects the conceptual linking of the discourse on human rights with that on health.

The Programme of Action called upon countries to strive to make accessible through the primary health-care system, reproductive health to all individuals of appropriate ages as soon as possible, and no later than the year $2015^{17}$. 
*M Rahman, A Rahman, TT Sajoni, et al

\section{Methodology}

This was a descriptive cross sectional study carried out in Dhamrai Upazila, Dhaka under Dhamrai union in Taltola, Choibaria, Kumrail, Islampur, Chandrail, Ambagan, Palara and Sadamath villages during the period $22^{\text {nd }}$ to $28^{\text {th }}$ December, 2012. The married women of reproductive age during data collection period were the study population. Total size of the sample was 534 and purposive in nature. Structured Questionnaire duly Pre-tested were the instrument for data collection. It was collected through face to face interview by 4th year MBBS students (AKMMC -02) of Anwer Khan Modern Medical College, Dhanmondi, Dhaka with prior filling up a consent form and signed by the respondent as a part of ethical consideration. It was processed and analyzed manually and by using computer.

\section{Results}

Table-I: Distribution of respondents by age $n=534$

\begin{tabular}{|c|c|c|}
\hline Age in years & Number of respondents & Percentage (\%) \\
\hline $15-19$ & 20 & 3.74 \\
\hline $20-24$ & 130 & 24.34 \\
\hline $25-29$ & 168 & 31.46 \\
\hline $30-34$ & 80 & 14.98 \\
\hline $35-39$ & 84 & 15.73 \\
\hline $40-44$ & 37 & 6.92 \\
\hline $45-49$ & 15 & 2.8 \\
\hline Total & 534 & 100 \\
\hline
\end{tabular}

About $86 \%$ respondents were found within age of 20-39 years . Mean age : 29years \& Standard deviation $: \pm 7.33$.

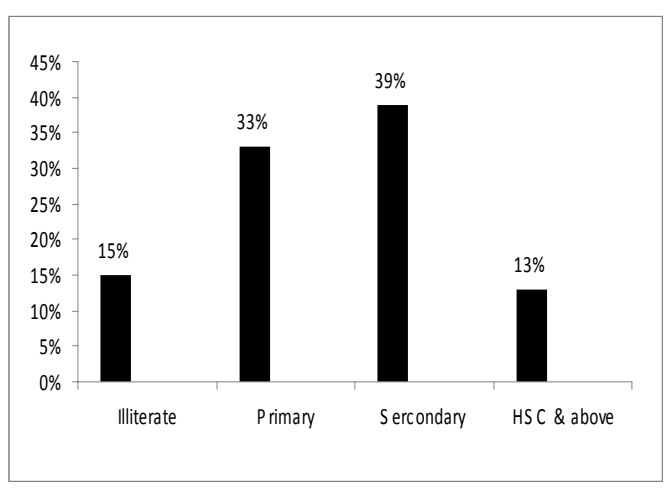

Figure 01: Distribution of respondents by level of education

Figure 01 shows that about $15 \%$ respondents were found illiterate and $33 \%, 39 \%$ respondents were found primary and secondary level of education respectively.

Table II Distribution of respondents by age at first issue \& number of children $n=534$

\begin{tabular}{|c|c|c|c|}
\hline $\begin{array}{r}\text { Age in years } \\
\text { first issue }\end{array}$ & $\begin{array}{c}\text { Number of } \\
\text { respondents }\end{array}$ & $\begin{array}{c}\text { Number of } \\
\text { children }\end{array}$ & $\begin{array}{c}\text { Number of } \\
\text { respondnets }\end{array}$ \\
\hline$<15$ & $\begin{array}{c}22 \\
(4.13)\end{array}$ & 01 & $\begin{array}{c}210 \\
(39.32)\end{array}$ \\
\hline $15-19$ & $\begin{array}{c}312 \\
(58.42)\end{array}$ & 02 & $\begin{array}{c}223 \\
(41.76)\end{array}$ \\
\hline $20-24$ & $\begin{array}{c}157 \\
(29.40)\end{array}$ & 03 & $\begin{array}{c}67 \\
(12.54)\end{array}$ \\
\hline $25-29$ & $\begin{array}{c}38 \\
(7.12)\end{array}$ & 04 & $\begin{array}{c}22 \\
(4.11)\end{array}$ \\
\hline $30-34$ & $\begin{array}{c}3 \\
(0.56)\end{array}$ & $>04$ & $\begin{array}{c}12 \\
(2.27)\end{array}$ \\
\hline$>34$ & 2 & & \\
& $(0.37)$ & & 534 \\
\hline Total & 534 & Total & $\begin{array}{c}534 \\
(100)\end{array}$ \\
\hline
\end{tabular}

N.B : Figure in the parenthesis indicates percentage.

About $58 \%$ respondents were found having their first issue at 15-19years of age. Mean age at first issue: 19 years. Standard deviation : \pm 3.5 . About 58\% respondents were found having 2-4 number of children and $39 \%$ respondents were found having one children only.

Table-III: Distribution of respondents' by antenatal advices \& investigations done during last delivery $\mathrm{n}=$ (Multiple response)

\begin{tabular}{|c|c|c|c|}
\hline $\begin{array}{c}\text { Antenatal } \\
\text { advices }\end{array}$ & $\begin{array}{c}\text { Number of } \\
\text { respondents }\end{array}$ & $\begin{array}{c}\text { Antenatal } \\
\text { investigations }\end{array}$ & $\begin{array}{c}\text { Number of } \\
\text { respondents }\end{array}$ \\
\hline Healthy diet & $\begin{array}{c}403 \\
(75.47)\end{array}$ & Urine R/M/E & $\begin{array}{c}277 \\
(51.87)\end{array}$ \\
\hline Personal hygiet & 363 & Stool R/M/E & 83 \\
$(67.92)$ & & $(15.54)$ \\
\hline Drug use & 315 & $\mathrm{Hb} \%$ & 196 \\
& $(58.98)$ & & $(36.70)$ \\
\hline Radiation & 20 & $\mathrm{HbsAg}$ & 82 \\
& $(3.74)$ & & $(15.36)$ \\
\hline Warning sign & 77 & Blood grouping & 229 \\
& $(14.42)$ & & $(42.89)$ \\
\hline & & Chest Xray & 20 \\
& & & $(3.75)$ \\
\hline & \multicolumn{2}{|c|}{ USG } & 227 \\
& & & $(42.50)$ \\
\hline Total & \multicolumn{2}{|c}{} \\
\hline
\end{tabular}

N.B : Figure in the parenthesis indicates percentage.

About $75 \%, 68 \%$ \& 59\% respondents received advices on healthy diet, personal hygiene and cautions about drug uses respectively. About $52 \%, 37 \%, 43 \%$ \& $42 \%$ respondents were advised to do urine $\mathrm{R} / \mathrm{M} / \mathrm{E}, \mathrm{Hb} \%$, blood grouping and USG respectively. 
Table-IV: Distribution of respondents' TT immunization, Complications during last delivery \& Problems related to reproductive system. $\mathrm{n}=534$

\begin{tabular}{|c|c|c|c|}
\hline \multirow{2}{*}{$\begin{array}{c}\text { Issues related to 1 } \\
\text { delivey }\end{array}$} & \multicolumn{2}{|c|}{ Number of respondents } & \multirow{2}{*}{ Total } \\
\cline { 2 - 3 } & Yes & No & \multirow{2}{*}{} \\
\hline TT immunizatio & 403 & 131 & 534 \\
& $(75.47)$ & $(24.53)$ & $(100)$ \\
\hline Complications duri & 165 & 369 & 534 \\
delivery & $(30.89)$ & $(69.10)$ & $(100)$ \\
\hline Problems related & 204 & 330 & 534 \\
reproductive syte & $(380$ & $(62)$ & $(100)$ \\
\hline
\end{tabular}

N.B : Figure in the parenthesis indicates percentage

About $79 \%$ respondent received TT immunization and $21 \%$ respondents did not receive any immunization. About $31 \%$ respondents faced complications during last delivery and $69 \%$ last delivery were without any complications and $38 \%$ respondents were suffering from problems related to reproductive system.

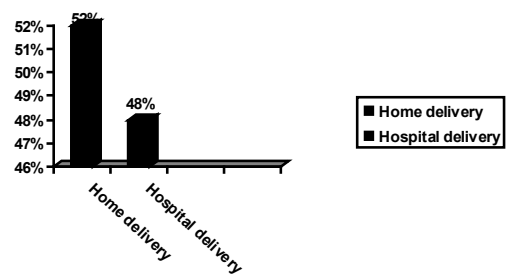

Figure 02: Distribution of respondents by place of last delivery Figure 02 shows that about $52 \%$ \& $48 \%$ respondents delivered their last issue at home and in the hospital respectively.

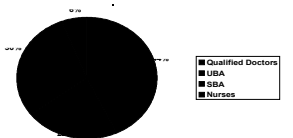

Figure 03: Distribution of respondents by designation of personnel by whom last delivery was conducted.

Figure 03 shows that About $44 \%$ respondents had their last delivery conducted by qualified doctors and about $22 \%, 30 \%$ and $6 \%$ respondents had their last delivery conducted by untrained birth attendant, skilled birth attendant and nurses respectively.

(N.B: UBA = Untrained Birth Attendant; SBA = Skilled Birth Attendant)

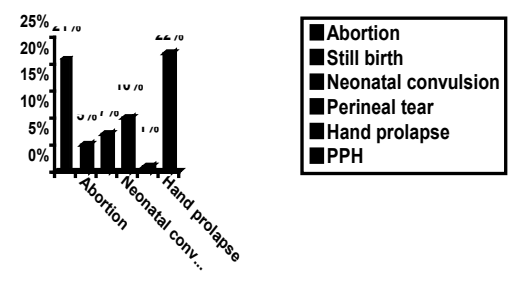

Figure 04 : Distribution of respondents by type of complications during last delibvery.

Figure 04 shows that Abortion (21\%), PPH (22\%) and Obstructed labor $(28 \%)$ were the most common complications during last delivery.

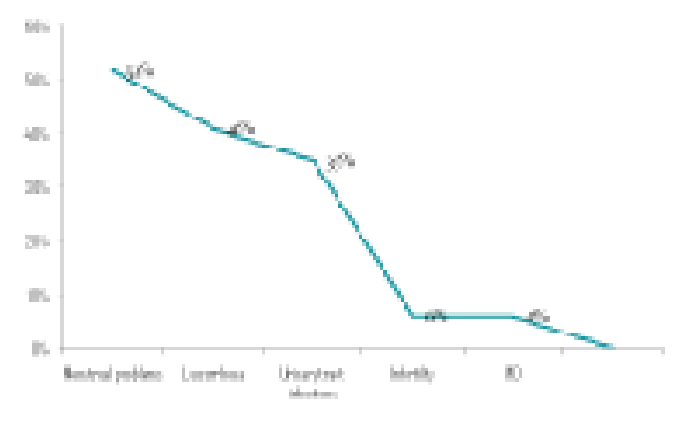

Figure 05 : Distribution of respondents by problems related to reproductive system.

Figure 05 shows that Menstrual problems (52\%), Leucorrhoea $(41 \%)$ and Urinary Tract Infections ( 35\%) were the most common sufferings related to reproductive system.

\section{Discussion}

In this study the mean age of the respondent was 29 years with SD of \pm 7.33 . Maximum proportion $(86 \%)$ of the respondents were found within the age group 20-39 years. About $91 \%$ respondents were muslims and 9\% were Hindu. Most of the respondents (99\%) were married and $0.56 \%, 0.38 \%$ were widow and divorced respectively.

The study shows that among the respondents $33 \%$, 39\% \& 13\% had completed Primary, Secondary and HSC above education respectively. About 15\% respondents were illiterate. a diverse finding was exposed by the MICS, 2009 of UNICEF ${ }^{12}$ where education rate was found around $72.0 \%$ among the females 15 - 
*M Rahman, A Rahman, TT Sajoni, et al

24 of years. This discrepancy can be explained by the facts that the MICS was conducted with a large sample countrywide and the finding was of a specific age group.

About $86 \%$ respondents were housewife and $11 \%, 1.14 \%$ were from service and business. The monthly income of the respondents in this study ranges from TK 3000 to more than TK 9000. Most of the respondents (44\%) were found monthly income from TK 3001 to TK 9000. However, (7\%) and (48\%) were found monthly income below TK 3000 and more than TK 9000 respectively. A comparable finding was revealed by the Centre for Integrated Rural Development of Asia and Pacific where majority of women $(82 \%)$ in rural areas were found unpaid family workers 12 .

About (58\%) respondents were found having 2-4 number of children and $39 \%$ respondents were found having one children only. About 58\% respondents were found having their first issue at 15-19 years of age. Mean age of the respondent having their first issue was 19 years with standard deviation \pm 3.5 . Similar finding was depicted through the survey of MOHFW where $75.0 \%$ of the girls were found married before the age of 16 . Because of early marriage majority $(69.8 \%)$ of the women had first child birth during adolescence (16-18 years) but the survey of MOHFW found that about $30 \%$ of female adolescents of Bangladeshi were already mothers ${ }^{6}$.

The study shows that $(75.6 \%)$ respondents received antenatal visit and about $(24.3 \%)$ respondents did not receive any antenatal visit during the last delivery. However, 50.74\% respondents received 1-3 number of antenatal visits and $33.17 \%, 16.09 \%$ received 4-6; 7-10 times of antenatal visit respectively. But the annual report of BDHS showed $48.7 \%$

About $75 \%, 68 \%$ \& $59 \%$ respondents received advices on healthy diet, personal hygiene and cautions about drug uses respectively. However, $52 \%, 37 \%, 43 \%$ and $42 \%$ respondents were advised to do urine $\mathrm{R} / \mathrm{M} / \mathrm{E}, \mathrm{Hb} \%$, Blood grouping and USG respectively.

The study reveals that $79 \%$ respondents received TT immunization and $21 \%$ respondents did not receive any immunization. But 50\% and $33 \%$ respondents received $2 \& 3$ doses of TT vaccine in their last pregnancy.

About $52 \%$ and $48 \%$ respondents delivered their last issue at home and hospital respectively. Relevant survey conducted by SVRS, BBS had different finding where home delivery was $87.1 \% 10$. The study also revealed that $44 \%$ respondents had their last delivery conducted by qualified doctor and $22 \%, 30 \%, 6 \%$ respondents had the last delivery conducted by untrained birth attendant, skilled birth attendant and nurses respectively. This finding varies with the finding of the survey of BDHS, which estimated $64.0 \%$ delivery conducted by untrained birth

attendants7. This discrepancy may be justified with the logic that this study was carried out with a small sample size in a semi urban community while BDHS conducted countrywide survey among large group of women.

\section{Conclusion}

Reproductive health is an emerging issue in Bangladesh as well as in the world. The study concludes that acceptance of antenatal check up during last pregnancy have the greatest potentiality to enhance the women reproductive health behaviour. Based on the result of the study, the level of reproductive health practice of the married women was not satisfactory. In our study, although $85 \%$ respondents are educated, but they are completely dependant to their husband for financial support. The study results ensure unawareness of the respondents about the proper age of first issue. Respondent's occupation, monthly family income, age at first issue and number of children have indirect significant effect on antenatalcheck up during last pregnancy.

\section{Recommendations}

Considering the findings of the present study, there are following recommendations:

- Women employment should be encouraged so that they could contribute financial support to their family.

- Respondents having 2or more children needs motivation in adopting family planning.

- Respondents having their first issue before 20 years of age needs motivation to differ their first issue through awareness program. 
Reproductive Health Practice of Married Women in the Rural

- Respondents preferring home delivery should ensured trained birth attendant or skilled nurses at the time of delivery to avoid complications.

- Early detection and treatment of reproductive tract infections and diseases need special attention by improved surveillance system in the study area.

- The government of Bangladesh as well as NGOs and International organizations should take many policies and programs to improve reproductive health issues.

\section{Acknowledgement}

It is our pleasure to acknowledge Principal \& Viceprincipal of Anwer Khan Modern Medical College to support in conducting this study. We also gratefully acknowledge Director of NIPSOM \& his support staff at Dhamrai THC in providing accommodation \& guidance during our stay at their premises. We are thankful for the support staff of Dhamrai THC as well. Thanks to our AKMMC-02 batch, students for their hard work from the very beginning in conducting and implementing this study protocol and their active participation for data collection in particular. Last but not least the people of the study area are gratefully acknowledged as key informants.

\section{References}

1. Bangladesh Maternal Health Services and Maternal Mortality Survey 2001.

2. Ahmed B. Differential Fertility in Bangladesh: A Path Analysis. Soci. Biol. 1982; 28(1-2): 102-110.

3. Bangladesh Bureau of Statistics. 2001 Statistical year book of Bangladesh. 22nd ed. Bangladesh. 2001

4. Barkat-t-Khuda, Reproductive Health in Rural Bangladesh: Policy and Programmatic, Vol. 1, Dhaka: MCH-FP Extension Project (Rural), ICDDR, B. 1998

5. Duncan OD. Path Analysis: Sociological Examples (Addenda). Casual Models in Social Science, Chicago, Aldine-Atherton Inc. 1977

6. Rashid KM, Rahman M, Hyder H. Textbook of Community Medicine and Public Health. MCH and Reproductive Health. 4th edition. RHM Publishers, Banani, Dhaka, Bangladesh; 2009.
7. Bangladesh Bureau of Statistics. Preliminary report 2001. Population Census of Bangladesh; 2002.

8. Report of Sample Vital Registration System (SVRS). Bangladesh Bureau of Statistics (BBS), Dhaka; 2004.

9. Effects of the Productive Role of Bangladeshi Women. Reported by Rebecca Sealand Katrina Manson, The Daily Independence, 13 March, 2009.

10. Family planning world wide datasheet 2002,Washington D.C., Population Reference Bureau, 2002.

11. Park K. Park's Textbook of Preventive and Social Medicine. 19th edition. Banarsidas Bhanot Publishers, 1167, Prem Nagar, Jabalpur, India; 2009: 55-56, 323-325.

12. Bangladesh Bureau of Statistics (BBS). Sample Vital Registration System (SVRS), Bangladesh; 2008.

13. Coale AJ. The Demographic Transition". In the Population Debate- Dimensions and Perspectives. United Nations. 1975; Vol. 1.

14. Chowdhury SNM, Kabir M, Hossain A. MR Programme in Bangladesh: Challenges for the Future". Background paper prepared for the project. A Situation Analysis of Bangladesh Menstrual Regulation Programme. Reproductive Health Alliance. 2002.

15. Mondal MNI, Hossain MK, Akter MsN. Reproductive health write of women in the Rural Area of Meherpur District in Bangladesh. J. Reprod. Infertility. 2010; 12(1): 23-32.

16. Bangladesh Maternal Health Services and Maternal Mortality Survey. National Institute of Population Research and Training (NIPORT), Ministry of Health and Family Welfare, ORC Macro, Calverton, Maryland, USA and Johns Hopkins University, USA. March 2002.

17. Save the Children. USA: Save the Children Federation; 2011. A Study on the Impact of the workshop on family planning conducted with the traditional and religious leaders in Nasirnagar Thana. 1993 Sept 19 [cited 2011 Mar 18]. Available on: http://pdf.usaid.gov/pdf docs/PNABU 648.pdf 